Research Article

\title{
Study on Time Factors in the Smoke Control Process of Highway Tunnel Fires
}

\author{
Guoping Zheng, ${ }^{1,2}$ Dapeng Xue ${ }^{\circ},{ }^{2}$ Yizhou Zhuang, ${ }^{1}$ and Yusheng $\mathrm{Zhu}^{2}$ \\ ${ }^{1}$ College of Civil Engineering and Architecture, Zhejiang University of Technology, Hangzhou 310014, China \\ ${ }^{2}$ College of Civil Engineering, Shaoxing University, Shaoxing 312000, China \\ Correspondence should be addressed to Dapeng Xue; rocpooh@vip.qq.com
}

Received 15 November 2020; Revised 10 August 2021; Accepted 3 November 2021; Published 30 November 2021

Academic Editor: Vasant Matsagar

Copyright (C) 2021 Guoping Zheng et al. This is an open access article distributed under the Creative Commons Attribution License, which permits unrestricted use, distribution, and reproduction in any medium, provided the original work is properly cited.

\begin{abstract}
Fire is the most deadly risk during tunnel operation. Early rapid response and a reasonable smoke control plan are very important to evaluate tunnel fire performance. In order to study the relevant time factors for smoke management in a highway tunnel, firstly, the logical sequence and time of the fire alarm system (FAS) startup are investigated and analyzed. Then, according to the onedimensional fluid mechanics model, the time rule of adjusting the airflow field in the tunnel from the normal operation stage to the emergency ventilation state is analyzed theoretically. Finally, the abovementioned theoretical formulas are verified through the employment of model experiments. The analysis shows that the time that passes from the start of the fire to when the exhaust fan is activated is close to 3 minutes. The time required to form a stable critical wind speed, however, is close to 7 minutes, which is longer than the 5 minutes it takes for the fire to reach its maximum temperature. Due to inertia, it takes about 0.5 to 2 minutes for the air velocity in tunnels of different lengths to drop from the traffic piston wind speed to the critical wind speed. If reverse smoke extraction is required, however, the duration is between 3 and 8 minutes. The conclusion is of guiding significance for the preparation of the emergency linkage control scheme for tunnels, as well as for the setting of initial boundary conditions for CFD fire simulations.
\end{abstract}

\section{Introduction}

As highway tunnels are relatively closed in their shape, fires in these tunnels can become extremely dangerous when not effectively controlled. In 1999, for example, 38 people were killed when a truck exploded and set off a fire in the Mont Blanc Tunnel in France. In 2001, 28 people were killed, and 128 were declared missing after a truck collision started a fire in the St. Geda Tunnel in Switzerland. And more recently, in 2007, 3 people were killed when 16 cars collided and ignited a fire in the Interstate No. 5 Tunnel in the United States.

The number of long tunnels in China is increasing day by day. By the end of 2018, there were 17,738 tunnels, with a total length of about $17,236.1 \mathrm{~km}$, each operating on highways in Mainland China (excluding Hong Kong, Macao, and Taiwan). Furthermore, over 110 extra-long tunnels, considered as those over $5 \mathrm{~km}$ in length, are expected to be built in China over the next 10 years. Worryingly, alongside this, road tunnel fire accidents in China also show a high incidence rate. In 2008, a transport vehicle in Dabaoshan Tunnel in Guangdong province burst into flames due to a xylene leakage, resulting in 2 deaths. In 2010, 24 people died when a bus caught fire in the Wuxi Huishan Tunnel. And just last recently, in 2019, 5 people were killed and 31 injured when a lorry caught fire in the Maoliling Tunnel in Zhejiang Province. There are many more incidents, and according to incomplete statistics, more than 90 people have been killed in road tunnel fires in China since 2010 alone, leaving many families with lingering painful memories.

Due to the advantages of low costs, simple operation and management, and good control effects on the backflow of flue gas, the longitudinal ventilation and smoke exhaust model is still the mainstream method for highway mountain tunnel ventilation and smoke exhaust systems. When there is a fire, it is generally understood that the vehicles downstream from the fire can quickly leave the tunnel, while for 
those trapped, the upstream direction of the fire is the best way to escape. At times like this, the upstream smoke needs to be controlled in terms of time and direction, and the monitoring room needs to take timely emergency measures and correctly direct the rescue personnel on the scene for effective rescue evacuation. In order to ensure the efficient and orderly operation of emergency measures and rescue work, it is imperative to implement a reasonable tunnel ventilation system linkage control strategy.

In recent years, a large number of scholars have done a lot of research on tunnel fires, especially on the smoke control aspect. In 2003, Ingason et al. [1,2] conducted five large-scale fire experiments in the Runehamar tunnel in Norway and developed a theoretical model to predict the heat release rate, among other parameters. In 2009, Chen et al. [3] studied the fire extinguishing effect of fine water mist under different ventilation speeds in the tunnel through small-scale experiments. In 2010, Lee et al. [4] studied the local smoke extraction system of the Busan-Juji immersed tube tunnel on a 1:20 scale model tunnel. In 2011, Li and Ingason [5] carried out a series of full- and reduced-scale experiments to analyze the influence of ventilation on the fire growth rate. In 2013, Yuan et al. [6] used the Froude number conservation method and a 1:15 scale model to study the fire diffusion characteristics of natural ventilation tunnels. In 2018, Yu et al. [7] carried out full-scale experiments to study the influence that the vertical diffusion of smoke in tunnels has on smoke control and, from this research, put forward relevant suggestions. In addition to model experiments, there are many other studies using numerical analysis software for fire dynamics (such as CFD and FDS) [8-13] as well as purely theoretical analysis [14].

In addition, many scholars have conducted research on fire detection. Rong et al. [15] proposed a fire detection algorithm based on features such as fire color. Muhammad et al. [16] proposed a camera dynamic channel selection algorithm based on a cognitive radio network. Ko [17] proposed a cumulative motion model based on integral imaging for tunnel fire smoke detection and then proved the robustness of the algorithm for smoke detection through various experiments. Yu et al. [18] proposed a video detection method based on foreground imaging and optical flow technology, which can simultaneously distinguish flame and smoke candidate areas and achieve a good detection effect. And Chiu et al. [12] optimized the fire detection system's performance and detection signals.

Furthermore, for tunnel fire rescue evacuations, scholars have also studied the tunnel evacuation simulation system $[11,19]$ and simulation methods [8], the establishment of an emergency evacuation simulation model [20], and the ideologies of self-rescue personnel [21, 22].

Despite all of these studies, two time-related boundary conditions have been ignored in the current experimental studies and CFD software-based numerical simulation of fire dynamics. The first is the start time of the fire alarm system (FAS) and ventilation equipment. The second is the time required, taking into consideration the inertia of the air in the tunnel, to get from the flow field in the normal operation stage to the stable flow field in the fire emergency ventilation stage. The fire rescue stage is a race with "death," which should be run without delay. For the analysis of tunnel fire safety, the detection, alarm, and equipment startup time should be taken into account [23]. Therefore, in order to better guide the performance-based designs for tunnel fire control, formulate efficient fire rescue evacuation plans, and improve the consistency between fire simulations and actual fire scenes, this paper intends to carry out analysis and research on the abovementioned two time-related boundary conditions.

\section{Operation Time Analysis of the FAS System and Linkage Equipment}

Once a fire occurs in a highway tunnel, the fire control system usually follows three steps: detection $\longrightarrow$ CCTV confirmation $\longrightarrow$ linkage control, as shown in Figure 1. In order to guide the performance-based fire design, the starting time and operating time of each stage and its equipment were investigated, and the conclusions are as follows:

(i) Stage 1. Detection stage: According to the Code for the Design of the Automatic Fire Alarm System [24], the response time of the dual-wavelength fire detector for a $0.5 \mathrm{~m}^{2}$ gasoline fire at a distance of $30 \mathrm{~m}$ is $\leq 10 \mathrm{~s}$, while for a $0.5 \mathrm{~m}^{2}$ gasoline fire at a distance of $60 \mathrm{~m}$, it is $\leq 20 \mathrm{~s}$. The response time of the grating fiber fire detector is $\leq 20 \mathrm{~s}$.

(ii) Stage 2. CCTV confirmation stage: The FAS system will automatically transfer the alarm's camera images to the computer or the large screen projection after the alarm goes off. The hard disk video recorder is activated in order to record the accident. The monitoring system's map shows the section where the accident is taking place and where the fire is and then sounds the alarm. The address and local name of the alarm and the linkage device are displayed. The monitor will judge the fire and confirm whether the alarm is a fire alarm, a false alarm, or a test. If it is a fire, the linkage control scheme will be implemented immediately to control the equipment such as the lanes, the lighting, the ventilation, and the information board. The confirmation time of the CCTV fire alarm is usually $60 \mathrm{~s}$. In order to improve the accuracy of fire identification and shorten the response time, currently applied technologies include convolutional neural network [16], sparse optical flow method [18], integral application model [25], geometric independent component analysis, and dynamic target tracking algorithm [15].

(iii) Stage 3. Linkage control stage: The response time of the main equipment involved is as follows:

(1) For long tunnels with a separate smoke exhaust to the vertical shafts (or inclined shafts), the time from starting to reaching the rated speed of the axial flow smoke exhaust fan installed on the ground or in the underground fan room is 


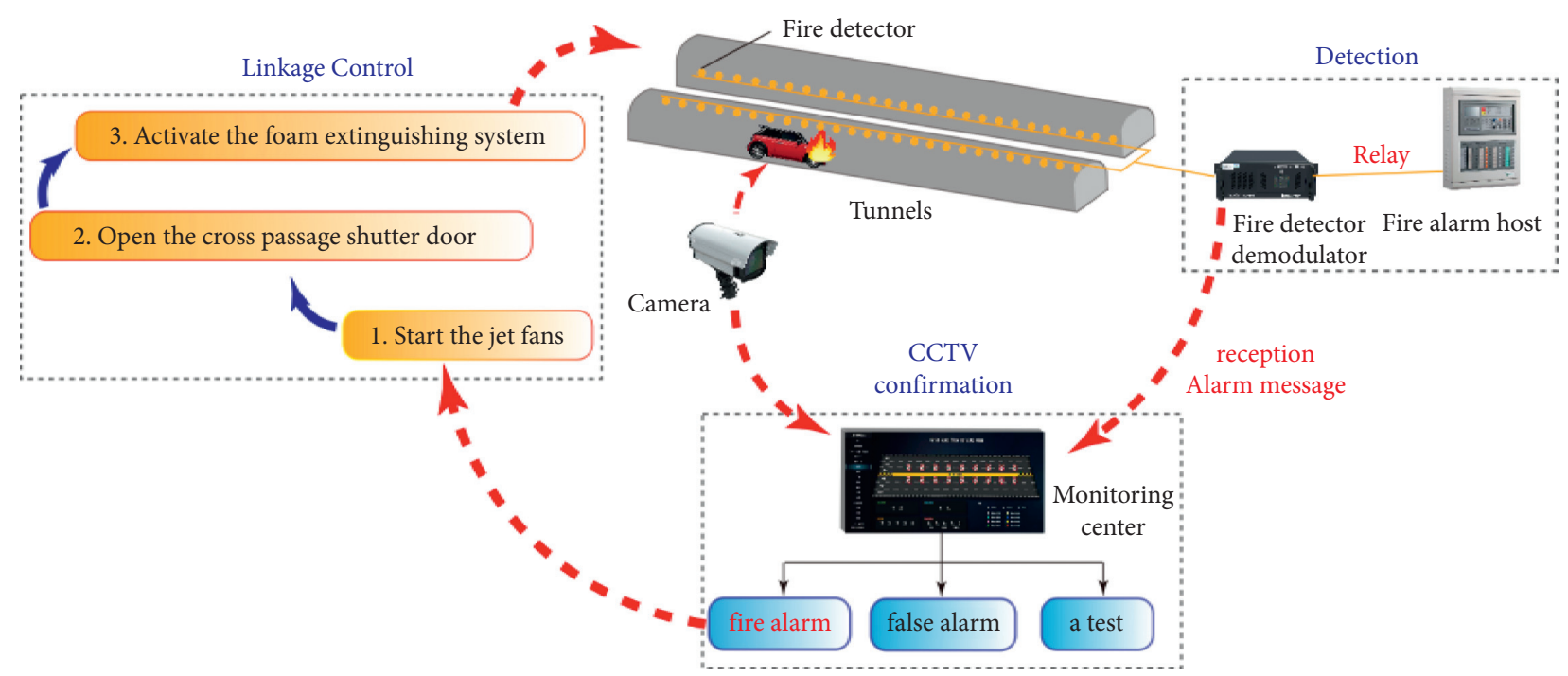

FIGURE 1: Linkage flow of tunnel fire control system.

usually $\leq 60 \mathrm{~s}$. The time for the fan inlet's electric combination air valve to go from fully closed to fully open is $\leq 20 \mathrm{~s}$, and the reverse time, from fully open to fully closed, is $\leq 60 \mathrm{~s}$. In addition, there are certain sequence requirements for the opening and closing of the fan and the air valve. When the fan is started, it is necessary to first open the fan's air valve and then start the fan. When the fan is shut down, it is necessary to stop the fan first and then close the fan's valve.

(2) The jet fan is the main power source that generates critical wind speed. However, due to the large impulse current sent at the starting of the fan (the instantaneous current in the hard starting mode is usually 7 times that of the full load current, while in the soft starting mode, it is only 3 times), a short delay is required for the starting of each group of fans, usually 60 120 s according to the transformer capacity.

(3) The electric fire shutter door at the crossing passage of the vehicle is usually required to improve its speed to more than $2 \mathrm{~m} / \mathrm{min}$; as its height is generally $5 \mathrm{~m}$, the longest time needed to open the shutter door is 2.5 minutes.

(4) A foam water spray fire extinguishing system is usually installed in soft soil tunnels. According to the code for the design of foam extinguishing systems [26], the system is equipped with automatic, manual, and emergency manual mechanical starting modes, with a response time under automatic control of $\leq 60 \mathrm{~s}$.

Following the above start time analysis for the linkage control device, the control time process table is drawn as shown in Figure 2. It is a series of movements, each of which takes a certain amount of time and has a certain sequence between them. The process from the start of the fire to the start of the smoke exhaust fan includes fire detection (20 s), alarm acknowledge (60 s), opening of the electric combined air valve of the smoke exhaust blower (20s), and opening of the smoke exhaust fan $(60 \mathrm{~s})$. The total time is $160 \mathrm{~s}$, nearly 3 minutes. When the jet fan is fully operational, the time needed to form a stable critical wind speed is about $400 \mathrm{~s}$, close to 7 minutes. However, according to the RABT and hydrocarbon fire standard heating curves (Figure 3), the fire in the tunnel usually reaches its peak power within 5 minutes. Therefore, time is of the essence, and furthermore, it is particularly important to have an efficient linkage control and strengthen the construction of the firefighting force of the tunnel management station.

\section{Time Factor Analysis for the Forming of a Stable Flow Field}

3.1. Traffic Piston Wind Speed. The tunnel ventilation system is mainly powered by two parts, with one being the traffic piston wind. When the wind from the traffic piston is insufficient to meet the ventilation health standards, it is supplemented by mechanical ventilation equipment, such as jet fans, which are large axial fans installed in shafts or inclined shafts. Traffic piston wind is the volume of air that flows in the direction of the car or train due to the piston effect of the car or train running in the tubular tunnel. Its size is related to the blocking ratio of the car in the tunnel, the driving speed of the car, the air resistance during driving, and the friction between the air and the tunnel wall among other factors. The research shows that the air volume from the traffic piston has the closest relationship with the operating speed, but that the sensitivity to the traffic flow and the tunnel length is weak. Therefore, taking the general twolane length of $5 \mathrm{~km}$ as an example, according to the equivalent impedance area of $A_{m}=2.04 \mathrm{~m}^{2}$, which is calculated by the traffic volume composition ratio, the speed of the traffic piston under different working conditions and with different traffic volumes is obtained, as shown in Figure 4. It can be seen that as long as the driving speed is not less than $60 \mathrm{~km} / \mathrm{h}$, the generated traffic piston wind speed is generally greater than $5 \mathrm{~m} / \mathrm{s}$. 


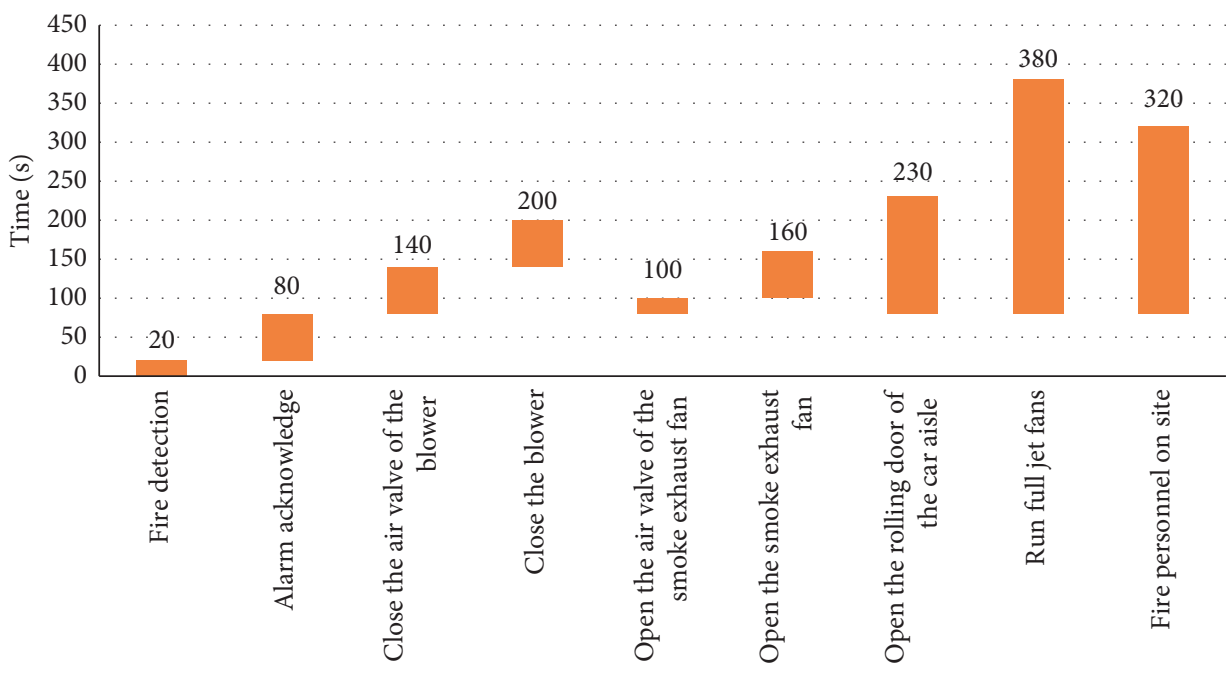

FIgURE 2: The starting time schedule of each firefighting equipment in the tunnel.

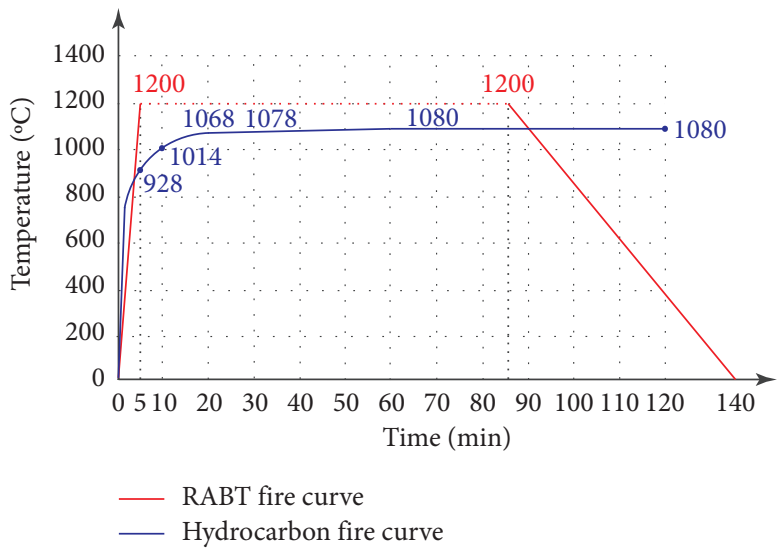

FIGURE 3: RABT and hydrocarbon fire standard heating curves.

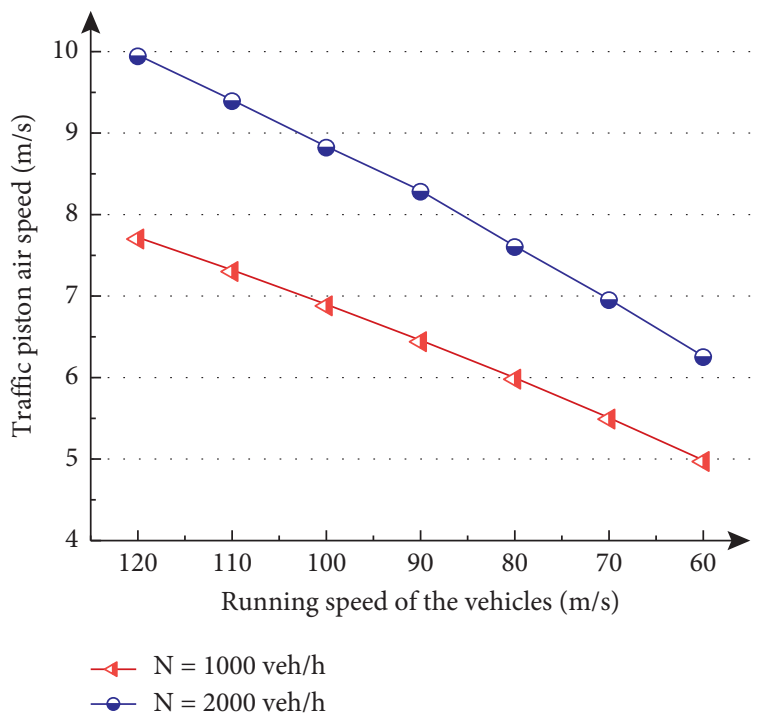

Figure 4: The speed of the traffic piston under different operating conditions. 
3.2. Calculation of Critical Wind Speed. Once a fire occurs in the tunnel and the tunnel enters the linkage control stage, the flow of traffic begins to stop, and the ventilation system enters the emergency ventilation mode, gradually adjusting the wind speed in the tunnel to the "critical wind speed" (hereinafter referred to as $v_{c r}$ ). $v_{c r}$ is the minimum exhaust ventilation wind speed required to prevent the countercurrent of fire from spreading upstream of the fire source, and it is the most effective means for smoke control under the longitudinal exhaust mode.

China's Guidelines for the Design of Ventilation of Highway Tunnels [27] (hereinafter referred to as "Guidelines") give different $v_{c r}$ according to different fire scales; for example, for a $30 \mathrm{MW}$ fire, the value is from $3 \mathrm{~m} / \mathrm{s}$ to $4 \mathrm{~m} / \mathrm{s}$. In addition to this, there are different empirical formulas in China and abroad. For example, Wu and Baker studied five kinds of rectangular cross-section tunnels that, from the aspect of experimentation and numerical simulation, have the same height but different widths, and then they proposed the calculation formula of $v_{c r}$ and so on. However, the time required to transition from the critical wind speed in the normal operation stage to the emergency ventilation mode is an important boundary condition for simulation analysis and experimental research; this research has not been described in the literature.

3.3. Time Analysis of Forming Positive. Taking the air fluid in the tunnel space as the research object, the following assumptions are made: (1) the fluid is an incompressible body; (2) the fluid is a continuous medium; (3) the fluid has a stable flow; and (4) the fluid has a constant density.
According to Newton's second law, the airflow movement law in the tunnel is shown in the following formula:

$$
F=m \cdot a=\rho \cdot A_{r} \cdot L \cdot \frac{\mathrm{d} v}{\mathrm{~d} t}
$$

The resistance, shown as $F$, is the product of the ventilation resistance $\left(\Delta P_{r}\right)$ in the tunnel and the sectional area $\left(A_{r}\right)$ in the tunnel carriageway space, namely:

$$
F=\Delta P_{r} \cdot A_{r}
$$

By combining formulas (1) and (2), the following formula can be obtained:

$$
\rho \cdot A_{r} \cdot L \cdot \frac{\mathrm{d} v}{\mathrm{~d} t}=\Delta P_{r} \cdot A_{r}
$$

where $\Delta P_{r}$ is the resistance of the unit area of the crosssection in the tunnel, which is mainly composed of three parts, namely, internal friction resistance loss $\left(\Delta P_{\lambda}\right.$; formula (4)) along the tunnel, local frictional resistance loss $\left(\sum \Delta P_{\xi i}\right.$; formula (5)) in the tunnel, and drag loss $\left(\Delta P_{t}\right.$; formula (6)) of stationary vehicles.

$$
\begin{aligned}
\Delta P_{\lambda} & =\left(\lambda r \cdot \frac{L}{D r}\right) \cdot \frac{\rho}{2} \cdot v^{2}, \\
\sum \Delta P_{\zeta i} & =\sum \zeta_{i} \cdot \frac{\rho}{2} \cdot v^{2}, \\
\Delta P_{t} & =\frac{A_{m}}{A_{r}} \cdot \frac{\rho}{2} \cdot n \cdot v^{2} .
\end{aligned}
$$

Then

$$
\Delta P_{r}=\Delta P_{\lambda}+\sum \Delta P_{\zeta i}+\Delta P_{t}=\left(\lambda_{r} \cdot \frac{L}{D_{r}}\right) \cdot \frac{P}{2} \cdot v^{2}+\sum \zeta_{i} \cdot \frac{P}{2} \cdot v^{2}+\frac{A_{m}}{A_{r}} \cdot \frac{P}{2} \cdot n \cdot v^{2}
$$

where $\zeta_{i}$ is the local resistance coefficient of the tunnel, and where the tunnel entrance is 0.5 , the exit is $1.0 ; A_{m}$ is the equivalent impedance area of the vehicles $\left(\mathrm{m}^{2}\right)$, and $n$ is the number of vehicles trapped in the tunnel. The following formula can therefore be obtained:

$$
\Delta P_{r}=\left(\lambda_{r} \cdot \frac{L}{D_{r}}\right) \cdot \frac{P}{2} \cdot v^{2}+\sum \zeta_{i} \cdot \frac{P}{2} \cdot v^{2}+\frac{A_{m}}{A_{r}} \cdot \frac{P}{2} \cdot n \cdot v^{2}=\left(1.5+\lambda_{r} \cdot \frac{L}{D_{r}}+\frac{A_{m}}{A_{r}} \cdot n\right) \cdot \frac{\rho}{2} \cdot v^{2} .
$$

Substitute formula (8) into formula (3) extract the time factor and integrate both sides to obtain the following formula:

$$
\Delta t=\int_{v_{r}}^{v_{c r}} \frac{\rho \cdot A_{r} \cdot L}{\left(1.5+\lambda r \cdot L / D r+A_{m} / A_{r} \cdot n\right) \cdot \rho / 2 \cdot v^{2} \cdot A_{r}} \cdot \mathrm{d} v=\frac{2 L}{\left(1.5+\lambda r \cdot L / D r+A_{m} / A_{r} \cdot n\right)}\left(\frac{1}{v_{c r}}-\frac{1}{v_{r}}\right) .
$$


3.4. Time Analysis of Forming Reverse $v_{c r}$. When the tunnel fire occurs at the entrance of the tunnel or there are stranded vehicles and individuals downstream from the fire point and it is confirmed by CCTV or on-site emergency treatment personnel that there are no stranded individuals upstream from the fire source, it is necessary to reverse the jet fan in order to generate reverse airflow and blow the fire smoke out from the nearest entrance. At this time, the airflow movement in the tunnel goes through two stages. In the first stage, by reversing the jet fans to form the ventilation resistance, the airflow in the tunnel gradually stagnated from the original driving direction of the car. In the second stage, the jet fan's power gradually raises the airflow velocity in the reverse direction to $v_{c r}$.

According to the Guidelines [27], the resistance or thrust of the jet fan is shown in formula (10). According to the thrust of the jet fan and the direction of the overall airflow in the tunnel, positive and negative values are taken, and "+" is taken in the opposite direction and "-" in the same direction. According to Newton's second law and in combination with formula (3), formula (11) of the airflow movement law in the tunnel is obtained.

$$
\begin{aligned}
& n_{j} \Delta P_{j}=n_{j} \cdot \rho \cdot v_{j}^{2} \cdot \frac{A_{j}}{A_{r}} \cdot\left(1 \pm \frac{v}{v_{j}}\right) \cdot \eta \\
& \left(n_{j} \cdot \rho \cdot v_{j}^{2} \cdot \frac{A_{j}}{A_{r}} \cdot\left(1 \pm \frac{v}{v_{j}}\right) \cdot \eta+\left(\lambda r \cdot \frac{L}{D r}+\sum \zeta_{i}\right) \cdot \frac{\rho}{2} \cdot v^{2}\right) \\
& \cdot A_{r}=L \cdot A_{r} \cdot \rho \cdot \frac{\mathrm{d} v}{\mathrm{~d} t} .
\end{aligned}
$$

$a=1 / 2\left(\lambda r \cdot L / D r+\sum \zeta_{i}\right), \quad b=-n_{j} \cdot v_{j} \cdot A_{j} / A_{r} \cdot \eta, \quad$ and $c=n_{j} \cdot v_{j}^{2} \cdot A_{j} / A_{r} \cdot \eta$ are defined. Furthermore, the length calculation can be obtained through integration as follows:

$$
\left\{\begin{array}{l}
\frac{L}{a} \cdot \frac{1}{\sqrt{c / a-b^{2} / 4 a^{2}}} \cdot\left[\arctan \frac{(v+b / 2 a)}{\sqrt{c / a-b^{2} / 4 a^{2}}}\right]_{-v_{r}}^{v_{c r}}, \quad \frac{c}{a}-\frac{b^{2}}{4 a^{2}}>0, \\
\frac{L}{\sqrt{b^{2}-4 a c}} \cdot \ln \left[\frac{2 a x+b-\sqrt{b^{2}-4 a c}}{2 a x+b+\sqrt{b^{2}-4 a c}}\right]_{-v_{r}}^{v_{c r}} \frac{c}{a}-\frac{b^{2}}{4 a^{2}} \leq 0,
\end{array}\right.
$$

where $n_{j}$ is the number of jet fans, which can be calculated by the pressure balance equation; $\Delta P_{j}$ is the lifting pressure $(\mathrm{N} /$ $\mathrm{m}^{2}$ ) of a single jet fan; $v_{j}$ is the outlet wind speed of the jet fan $(\mathrm{m} / \mathrm{s}) ; A_{j}$ is the outlet area of the jet fan $\left(\mathrm{m}^{2}\right)$; and $\eta$ is the reduction coefficient of friction loss at the position of the jet fans, which is set as 0.7 when $2-3$ jet fans are installed in a group on the same section of the tunnel.

\section{Study of Model Experiments}

In order to verify the accuracy of the above theoretical formulas, model experiments are carried out in this paper. The main contents of the experiment are: under the influence of the resistance of the natural wind simulated by the fan along the tunnel, the time when the wind speed drops from a certain starting speed to a certain target speed or the time when the wind speed rises to a certain target speed in reverse direction under the action of the jet fans is recorded; The formulas are verified by comparing the experimental and theoretical time data.

4.1. Experimental Model. The experimental model (Figures 5-7) is formed up of the tunnel model, an axial flow fan, a fan converter, wind speed sensors, differential pressure sensors, five sets of grids (Table 1), and a PLC control system. The line tunnel model is made of steel, 2 meters per section, with a section area of $0.69 \mathrm{~m}^{2}$.

The wind speed sensors adopt a JY-YL2 impeller type, and their range is from 0 to $40 \mathrm{~m} / \mathrm{s}$. Differential pressure sensors adopt a 4-20 mA signal, and a YX-Fy-01G type, with a measuring range from 0 to $200 \mathrm{~Pa}$. A wind speed sensor and a differential pressure sensor are installed at the left and right mouths of the cave, respectively, which are connected to the PLC control system in order to store and display the wind speed value that changes with time in real time. The output air volume of the axial fan is $18.1 \mathrm{~m}^{3} / \mathrm{s}$. The fan outlet's wind speed and the wind speed in the tunnel are adjusted through a frequency converter. The frequency is between 0 and $50 \mathrm{~Hz}$, which can make the wind speed stable at any fixed value. The experimental steps were as follows:

(i) The tunnel model was assembled, and two lengths were used in the experiment, which were $20 \mathrm{~m}$ and $30 \mathrm{~m}$, respectively.

(ii) The grid was installed in the middle of the model, and the distance between the grid and the openings at both ends was greater than 3 times the tunnel's equivalent diameter. The types of grids used in the experiment are shown in Table 1.

(iii) The fan was turned on and the frequency converter was adjusted to obtain a stable wind speed of $9 \mathrm{~m} / \mathrm{s}$ in the tunnel.

(iv) The fan was turned off, and timing was started. The PLC system measured the wind speed curve changing with time in real time and recorded the duration it took to reach different target speeds.

4.2. Experimental Model. First, $1.5+\lambda_{r} \cdot L / D_{r}+A_{m} / A_{r} \cdot n$ in formula (9) is taken as the comprehensive resistance 


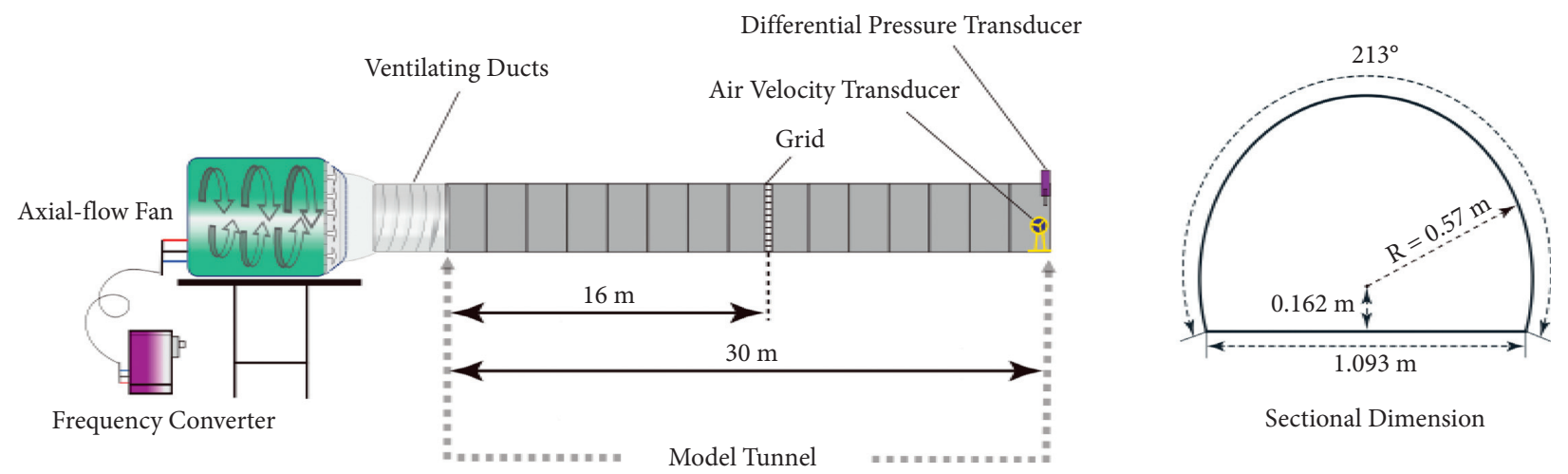

FIgURE 5: Tunnel simulation system.

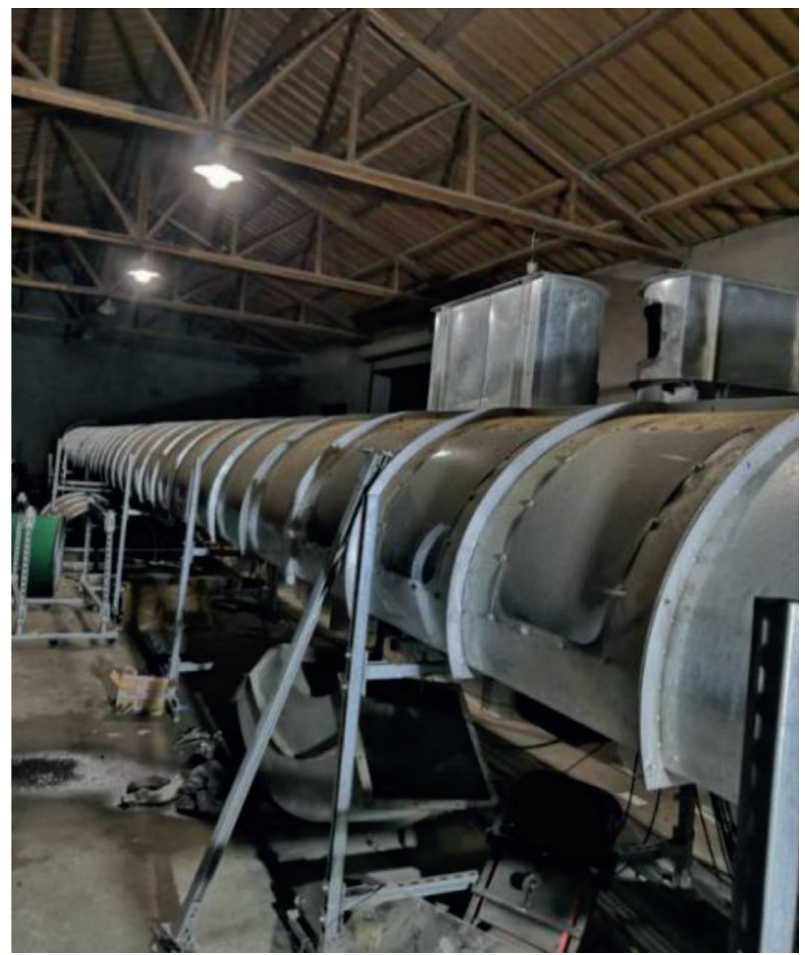

Figure 6: Site layout of the tunnel model.

coefficient $\left(\lambda_{c}\right)$. After the grid is installed in the model tunnel, upstream measuring point 1 and downstream measuring point 2 are set outside the influence range on both sides of the grid. The distance between measuring points 1 and 2 is $L$, and the wind speed at any point $x$ between measuring points 1 and 2 is set as follows:

$$
v_{x}=v_{1}-\left(v_{1}-v_{2}\right) \frac{x}{L}
$$

The following formula can be obtained from the fluid energy equation:

$$
\Delta P=P_{1}-P_{2}=\int_{0}^{L} \lambda \frac{\mathrm{d}_{x}}{\mathrm{D}} \frac{\rho}{2} v_{x}^{2} .
$$

Formula (15) can be derived from formulas (13) and (14). When the average wind speed of the front and back section is

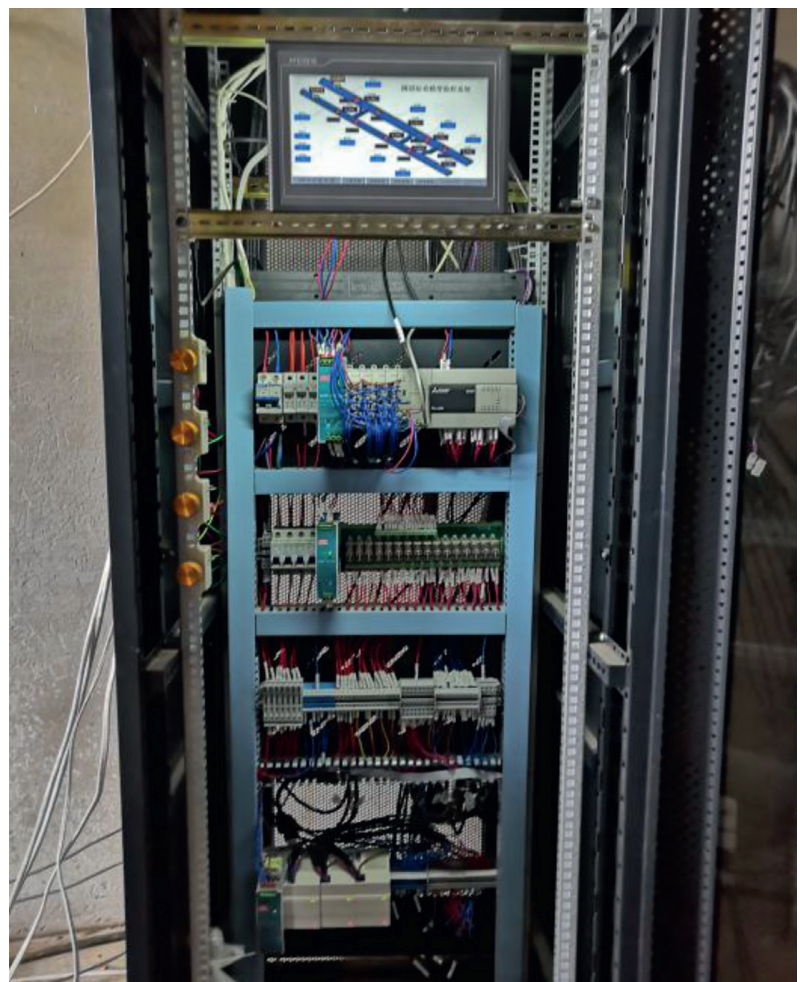

Figure 7: PLC control system.

TABLE 1: The parameters of the grids used in the experiment.

\begin{tabular}{llllll}
\hline Number & 1 & 2 & 3 & 4 & 5 \\
\hline Wire diameter/mm & 4 & 3 & 2 & 2 & 2 \\
Aperture/mm & 8 & 6 & 4 & 3 & 2 \\
\hline
\end{tabular}

close, that is, $v_{1} \approx v_{2}$, then let $v=v_{1}+v_{2} / 2$; the comprehensive resistance coefficient can be calculated as follows:

$$
\lambda=\frac{2 D\left(P_{1}-P_{2}\right)}{\rho L v^{2}} .
$$

For a particular tunnel, if the equivalent diameter $D$ and tunnel length $L$ are constant, then 


$$
\lambda_{c}=\frac{\lambda L}{D}=\frac{2\left(P_{1}-P_{2}\right)}{\rho v^{2}} .
$$

Therefore, for a model tunnel of a certain length, its value is the quotient of the pressure difference between the two ends of the tunnel and $\rho / 2 \cdot v^{2}$. Thus, the comprehensive resistance coefficient corresponding to each grid is obtained as shown in Table 2:

\subsection{Experimental Results}

4.3.1. Comprehensive Resistance Coefficient $\left(\lambda_{c}\right)$. Under the influence of the comprehensive resistance coefficient of the tunnel, the wind speed in the tunnel drops to the target wind speed. The comprehensive resistance coefficient is an important influencing factor in this process. Therefore, it is of great significance to study the change rule of the total time with the increase of the comprehensive resistance coefficient.

In the experiment, the comprehensive resistance coefficient is changed by installing the grids, and the total time under each working condition is measured. According to Figure 8, for a tunnel model with a length of $L=20 \mathrm{~m}$, when the target wind speed is $v_{c r}=1 \mathrm{~m} / \mathrm{s}$ and the comprehensive resistance coefficient $\lambda_{c}$ increases from 2.058 to 3.907, the total time decreases from $22.12 \mathrm{~s}$ to $13.53 \mathrm{~s}$. When the target wind speed is $v_{c r}=1.5 \mathrm{~m} / \mathrm{s}$, the total time decreases from $13.12 \mathrm{~s}$ to $8.32 \mathrm{~s}$; When the target wind speed is $v_{c r}=2 \mathrm{~m} / \mathrm{s}$, the total time decreases from $10.11 \mathrm{~s}$ to $6.06 \mathrm{~s}$. According to Figure 9, for a tunnel model with a length of $L=30 \mathrm{~m}$, when the target wind speed $v_{c r}$ is $1 \mathrm{~m} / \mathrm{s}, 1.5 \mathrm{~m} / \mathrm{s}$, and $2 \mathrm{~m} / \mathrm{s}$, the total time decreases from $29.72 \mathrm{~s}, 18.72 \mathrm{~s}$, and $13.41 \mathrm{~s}$ to $15.96 \mathrm{~s}$, $9.71 \mathrm{~s}$, and $7.16 \mathrm{~s}$, respectively. It can be seen that the total time needed for the airflow in the tunnel to reach the forward target wind speed always decreases gradually with the increase of the comprehensive resistance coefficient of the tunnel. According to the fitted curve, the variation rule is consistent with the derived formula (9). Therefore, the reliability of the formula is verified, and the total time is inversely proportional to the comprehensive resistance coefficient.

4.3.2. Target Wind Speed $\left(v_{c r}\right)$. Target wind speed is an important parameter to be considered during experimentation. The total time it takes to reach the target wind speed in the tunnel is bound to vary, but under the influence of the comprehensive resistance coefficient, tunnel length, and other factors, the variation rule with the change of the target wind speed and the compatibility with the formula have not been determined.

Combining Figures 8 and 9, when the tunnel length and the comprehensive resistance coefficient are fixed, the total time for the wind flow in the tunnel to reach the target wind speed increases gradually with the decrease of the target wind speed. For different target wind speeds, the variation trend of total time with the comprehensive resistance coefficient is consistent with the theoretical formula curve, that is, the relationship between the total time and the inverse of
TABle 2: Comprehensive resistance coefficients of various conditions.

\begin{tabular}{lcc}
\hline Number & $L=20 \mathrm{~m}$ & $L=30 \mathrm{~m}$ \\
\hline No grid & 1.872 & 2.058 \\
Grid 1 & 2.174 & 2.512 \\
Grid 2 & 2.337 & 2.756 \\
Grid 3 & 2.523 & 3.035 \\
Grid 4 & 2.802 & 3.453 \\
Grid 5 & 3.105 & 3.907 \\
\hline
\end{tabular}

the target wind speed of the tunnel has a linear function, which therefore verifies the reliability of the formula.

4.3.3. Length of Tunnel. Tunnel length is also an important factor affecting the wind speed reduction from the original wind speed to the target wind speed. The experiment simulated the tunnel model with the length of $20 \mathrm{~m}$ and $30 \mathrm{~m}$, analyzed the differences and rules between them, and compared them to the theoretical data in order to obtain the general rule for the correlation of wind speed change and the length of the tunnel.

Figures 8 and 9 show the total time it took from the initial wind speed of $9 \mathrm{~m} / \mathrm{s}$ to the target wind speed of $1 \mathrm{~m} / \mathrm{s}$, $1.5 \mathrm{~m} / \mathrm{s}$, and $2 \mathrm{~m} / \mathrm{s}$, respectively, with the change of comprehensive resistance coefficient in tunnels of different lengths of $20 \mathrm{~m}$ and $30 \mathrm{~m}$. It can be seen that when the target wind speed and the comprehensive resistance coefficient are fixed, the total length of a $30 \mathrm{~m}$ tunnel is always greater than a $20 \mathrm{~m}$ tunnel. The total time values of both are in line with the theoretical curve made by formula (9), and the experimental data trend is consistent with the formula data trend.

For formula (9), when taking the ordinary two-lane tunnel as an example, if $A_{r}$ is taken as $68.00 \mathrm{~m}^{2}, D_{r}$ as $8.3 \mathrm{~m}$, $A_{m}$ as $2.04 \mathrm{~m}^{2}, \lambda_{r}$ as $0.02, n$ as 100 vehicles, and $v_{c r}$ and $v_{r}$ as $3.5 \mathrm{~m} / \mathrm{s}$ and $6.0 \mathrm{~m} / \mathrm{s}$, respectively. According to the Guidelines [27], the calculation formula of the number of jet fans $\left(n_{j}\right)$ is as follows:

$$
n_{j}=\operatorname{Int}\left[\frac{1 / 2\left(1.5+\lambda_{r} \cdot L / D_{r}\right) \cdot v_{c r}^{2}}{\Delta P_{j}} \times \frac{1}{2}+1\right] \times 2 .
$$

For two- and three-lane tunnels of different lengths, the time required from the traffic piston wind speed to the critical wind speed $\left(v_{c r}\right)$ is shown in Figure 10.

As can be seen from Figure 10, with the increase of tunnel length, the time required for the airflow velocity in the tunnel to decrease from the traffic piston wind speed to the critical wind speed gradually increases, but the increase rate decreases. According to the curve trend, when the tunnel exceeds 8,000 meters, the time increment is relatively small. In general, this process takes about 0.5 to 2 minutes.

4.4. Experiment of Forming Reverse $v_{c r}$. In order to simulate the exhaust process, when it is necessary to blow smoke in the reverse direction, the experimental system layout is as shown in Figure 11. At the left entrance of the tunnel, a ventilator cover and two ventilation ducts with a diameter of 


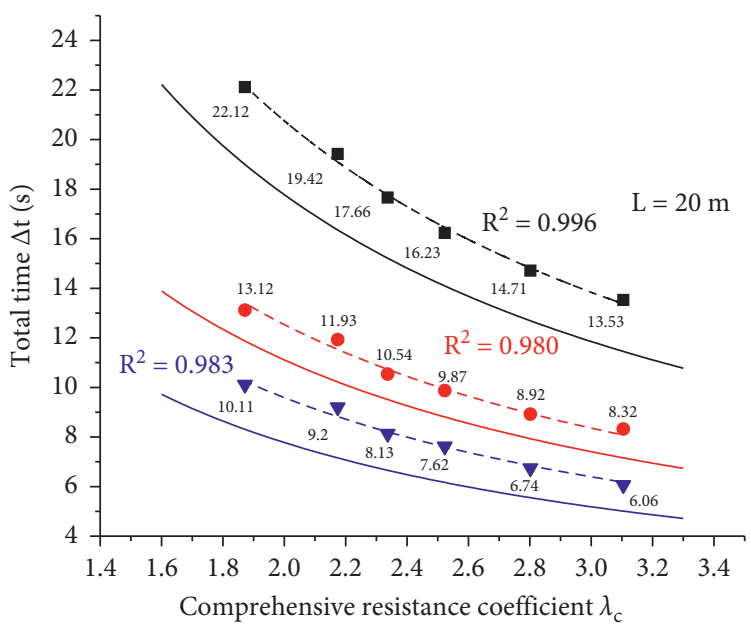

- Experimental data $\left(\mathrm{v}_{\mathrm{cr}}=1 \mathrm{~m} / \mathrm{s}\right)$

- Experimental data $\left(\mathrm{v}_{\mathrm{cr}}=1.5 \mathrm{~m} / \mathrm{s}\right)$

V Experimental data $\left(\mathrm{v}_{\mathrm{cr}}=2 \mathrm{~m} / \mathrm{s}\right)$

- - - Fitting curve

— Theoretical curve

- - Fitting curve

- Theoretical curve

- - - Fitting curve

— Theoretical curve

Figure 8: $L=20 \mathrm{~m}$, the total time under different $\lambda_{c}$.

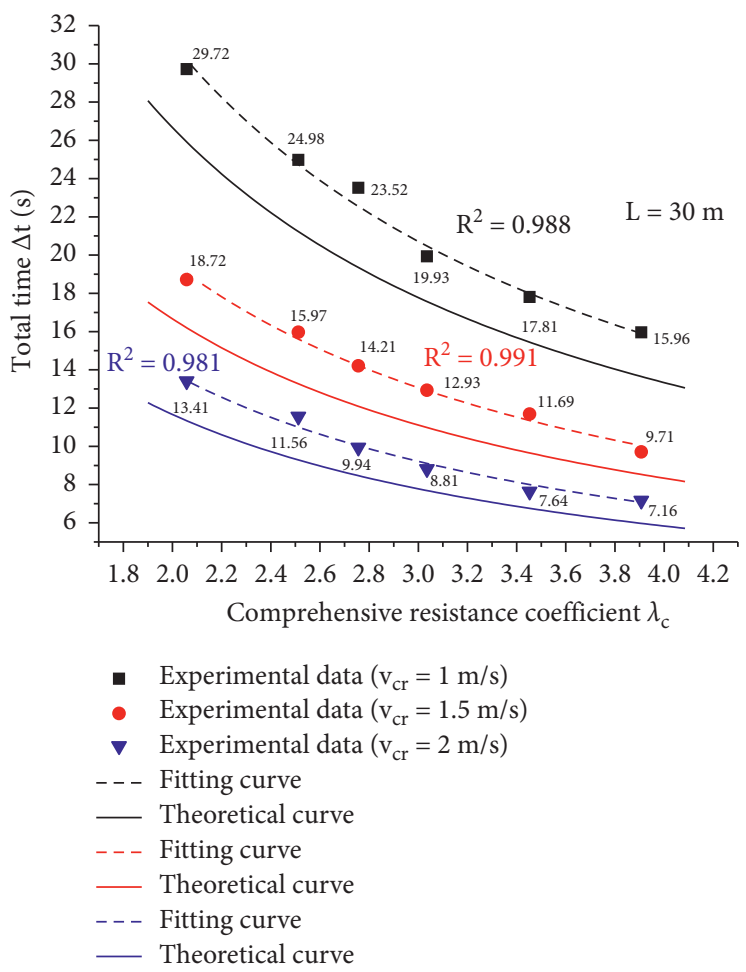

Figure 9: $L=30 \mathrm{~m}$, the total time under different $\lambda_{c}$.

$110 \mathrm{~mm}$ were installed at the fan's air outlet. The ducts were extended horizontally above the entrance (as shown in Figure 12) in order to simulate the tunnel's jet fans, and the wind speed at the exit of the fan was adjusted through a frequency converter. At the right entrance of the tunnel, the wind cover was connected to the axial-flow fan, and the wind 


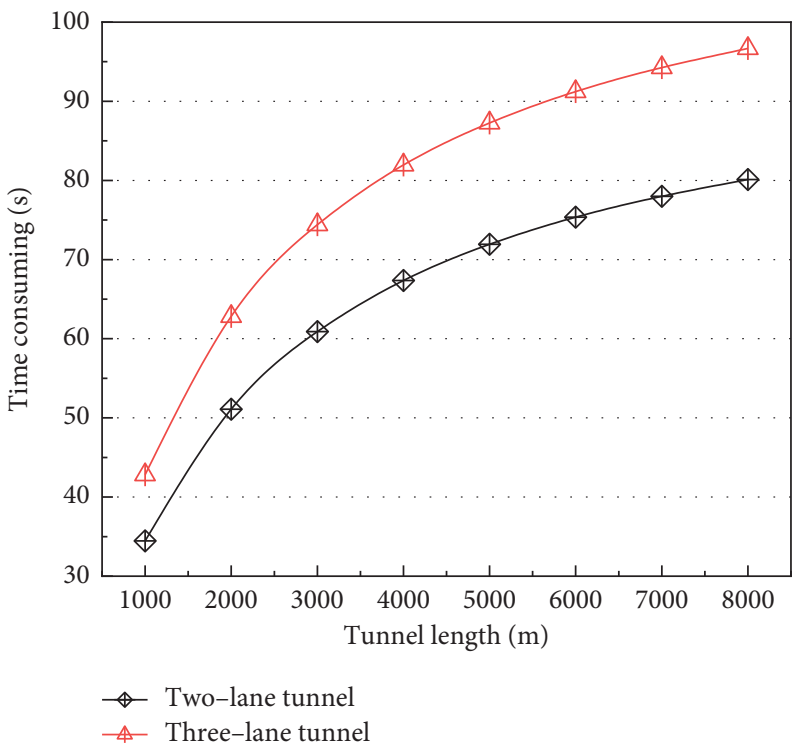

FIgURE 10: Time required for different lengths of tunnels.

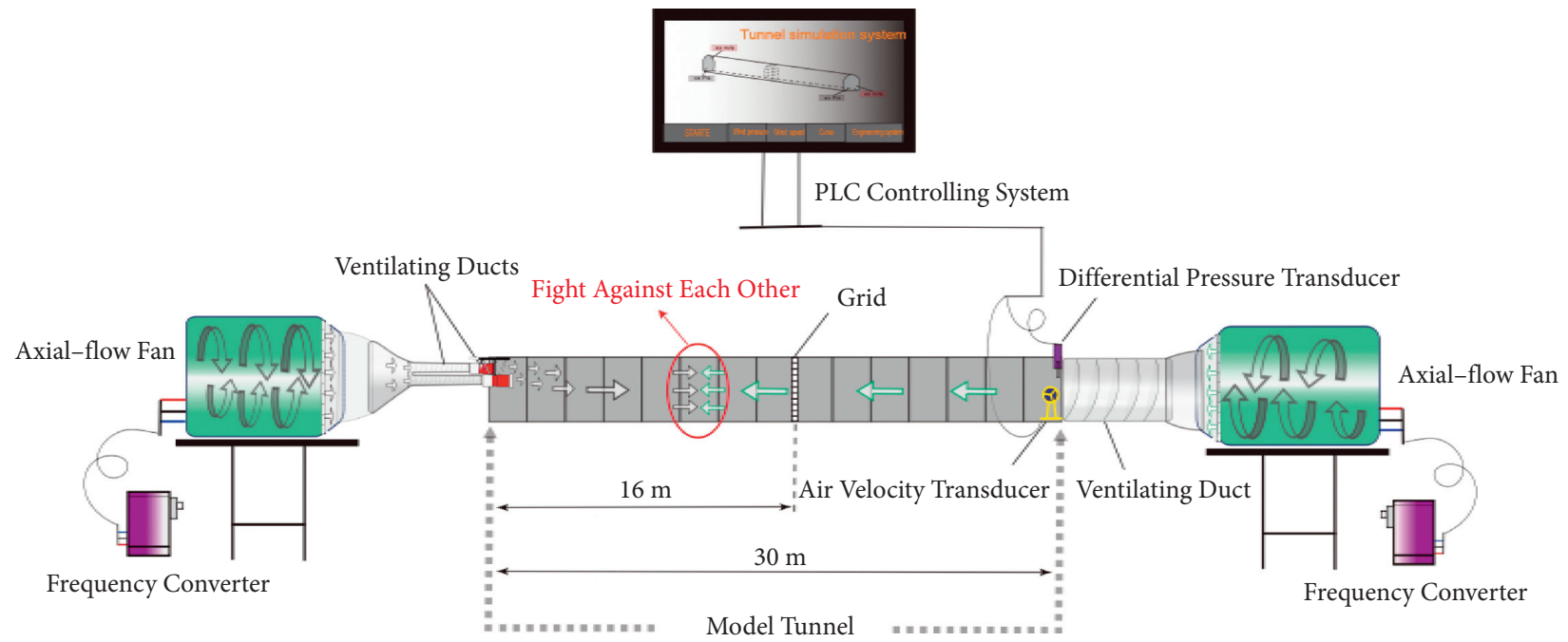

Figure 11: Layout of experimental system.

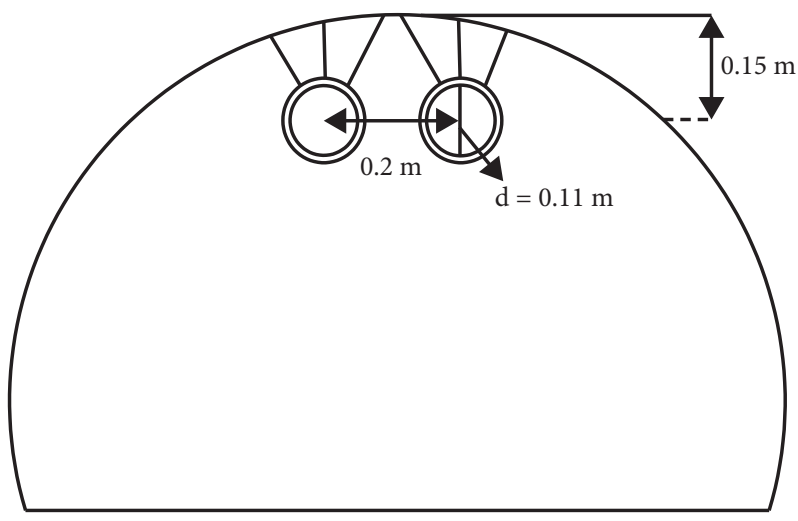

Figure 12: Position of jet fans. 
speed was adjusted through another frequency converter to simulate the initial traffic piston wind $\left(v_{r}\right)$ of the tunnel.

4.5. Experimental Results. With the change of the tunnel's comprehensive resistance coefficient and the starting wind speed of the jet fans, the time from the initial wind speed $\left(v_{r}\right)$ to the formation of the reverse target wind speed $\left(v_{c r}\right)$ was obtained in the tunnel with the different lengths of $20 \mathrm{~m}$ and $30 \mathrm{~m}$.

The wind speed of the jet fans is taken as an independent variable, while the time is taken as a dependent variable in the derived formula. The curve of the change of time with the wind speed of the jet fans and the error lines of $\pm 10 \%$ are plotted, and the time data obtained by the experiment is compared with the data of the formula curve. The results are shown in Figure 13.

4.5.1. Outlet Wind Speed of Jet Fans. In order to reverse the wind direction in the tunnel and achieve the reverse target wind speed, the jet fans, as the only equipment providing impetus in this process, must be considered as an important factor affecting the total time. Therefore, it is necessary to discuss the rule change of the airflow in the tunnel from the initial wind speed to the reverse target wind speed with the increase of the wind speed at the exit of the jet fans.

As shown in Figures 13(a)-13(f), when the tunnel length and the comprehensive resistance coefficient are fixed, the total time it takes for the airflow in the tunnel to go from the initial wind speed to the reverse target wind speed decreases with the increase of the wind speed from the jet fans. At the same time, the decreasing amplitude of the jet fan wind speed also decreases the total time, that is to say: when the wind speed of the jet fan increases from $10 \mathrm{~m} / \mathrm{s}$ to $20 \mathrm{~m} / \mathrm{s}$, the decrease value of the total time is nearly twice as much as the decrease value of the total time from $20 \mathrm{~m} / \mathrm{s}$ to $30 \mathrm{~m} / \mathrm{s}$. When the jet fan's exit wind speed is greater than $30 \mathrm{~m} / \mathrm{s}$, the total time reduction for a $30 \mathrm{~m}$ tunnel will be less than $15 \mathrm{~s}$, and the total time for a $20 \mathrm{~m}$ tunnel will be less than $10 \mathrm{~s}$. So when there is a fire in the tunnel, in order to reverse the wind flow as quickly as possible, the jet fans should be adjusted to more than $30 \mathrm{~m} / \mathrm{s}$ from the first time.

4.5.2. Comprehensive Resistance Coefficient $\left(\lambda_{c}\right)$. The resistance present in a long straight tunnel is always in the opposite direction to the airflow. Therefore, before the wind flow is reversed, the frictional resistance is opposite to the jet fan, but after the reversal, the two flow in the same direction. Therefore, the change of the comprehensive resistance coefficient is bound to have a certain influence on the total time it takes for the tunnel to reach the reverse target wind speed. Thus, it is necessary to study the change rule of the total time with the change of the comprehensive resistance coefficient under different conditions.

As shown in Figures 13(a)-13(f), when the tunnel length and the wind speed of the jet fan are fixed, the total time from the initial wind speed $\left(v_{r}\right)$ to the reverse target wind speed $\left(v_{c r}\right)$ increases with the increase of the comprehensive resistance coefficient. However, the higher the wind speed of the jet fans, the smaller the time difference between the tunnels with different comprehensive resistance coefficients. For a $20 \mathrm{~m}$ tunnel, the time difference between the tunnel without a grid and the tunnel with grid 1 is $5.9 \mathrm{~s}$ when the wind speed of the jet fans is at $10 \mathrm{~m} / \mathrm{s}$, while the time difference between the two is reduced to $1.88 \mathrm{~s}$ when the wind speed of the jet fans is at $30 \mathrm{~m} / \mathrm{s}$. It can be inferred that as the jet fans' wind speed continues to increase, the time difference between the tunnels with different comprehensive resistance coefficients will continue to shrink and can even approach zero. Therefore, the influence of the tunnel comprehensive resistance coefficient on the total time can be reduced with the increase of the wind speed from the jet fans. Furthermore, according to the curve of the derived theoretical formula, the general rule shown by the experimental data is consistent with the curve of the theoretical formula, which thus verifies the reliability of the formula.

4.5.3. Length of Tunnel. The length of the tunnel is also an important factor affecting the wind speed of tunnel wind. Due to the model's limited experimental conditions, the experiment only simulates tunnels with a length of $20 \mathrm{~m}$ or $30 \mathrm{~m}$. By analyzing the differences and laws between the two, and comparing them with the theoretical data derived from the formula, the general law for the changes that come with the length of the tunnel is deduced.

When the comprehensive resistance coefficient of the tunnel is constant, the total time taken for the $30 \mathrm{~m}$ tunnel to reach the reverse target wind speed is greater than the total time taken for the $20 \mathrm{~m}$ tunnel. Furthermore, the time difference between the two decreases with the increase of the wind speed of the jet fans. When the wind speed of the jet fans is at $10 \mathrm{~m} / \mathrm{s}$, the time difference between the two is greater than $10 \mathrm{~s}$. When the wind speed of the jet fans increases to $30 \mathrm{~m} / \mathrm{s}$, the time difference between the two is less than $5 \mathrm{~s}$. When the wind speed of the jet fans is greater than $30 \mathrm{~m} / \mathrm{s}$ and is continuing to increase, the time difference between the two will approach zero. Furthermore, according to the curve of the derived theoretical formula, it is consistent with the general rule of the experimental data, and the error is also small, which thus verifies the reliability of the formula.

For formula (12), when taking the ordinary two-lane tunnel as an example, with $A_{j}$ therefore being $0.9852 \mathrm{~m}^{2} ; v_{j}$ being $30 \mathrm{~m} / \mathrm{s} ; D_{r}$ being $3 \mathrm{~m} ; \lambda_{r}$ being $0.02 ; v_{c r}$ and $v_{r}$ being $3.5 \mathrm{~m} / \mathrm{s}$ and $6.0 \mathrm{~m} / \mathrm{s}$, the number of jet fans $\left(n_{j}\right)$ is obtained according to formula (17). The time it takes for the traffic piston wind in its normal operation stage to go to the formation of reverse $v_{c r}$ for two- and three-lane tunnels with different lengths is obtained, as shown in Figure 14.

As can be seen from this figure, with the increase of the tunnel length, the time needed for the airflow velocity in the tunnel to change from the traffic piston wind state in its normal operation stage to the reverse critical wind speed gradually increases, but the increase rate decreases. The time increment when the tunnel exceeds 8,000 meters is relatively small, and in general, this process takes about 3 to 7 minutes. 

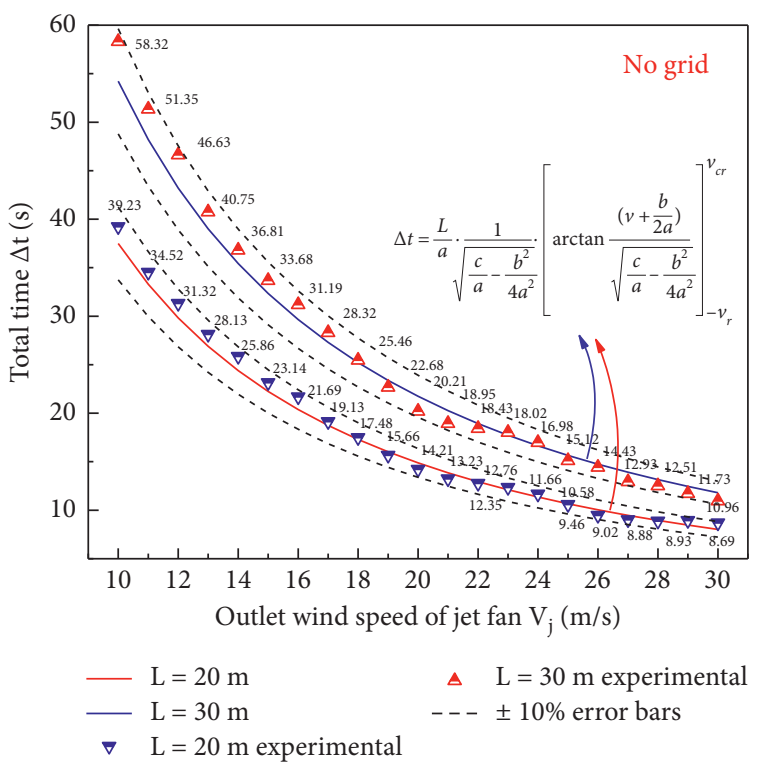

(a)

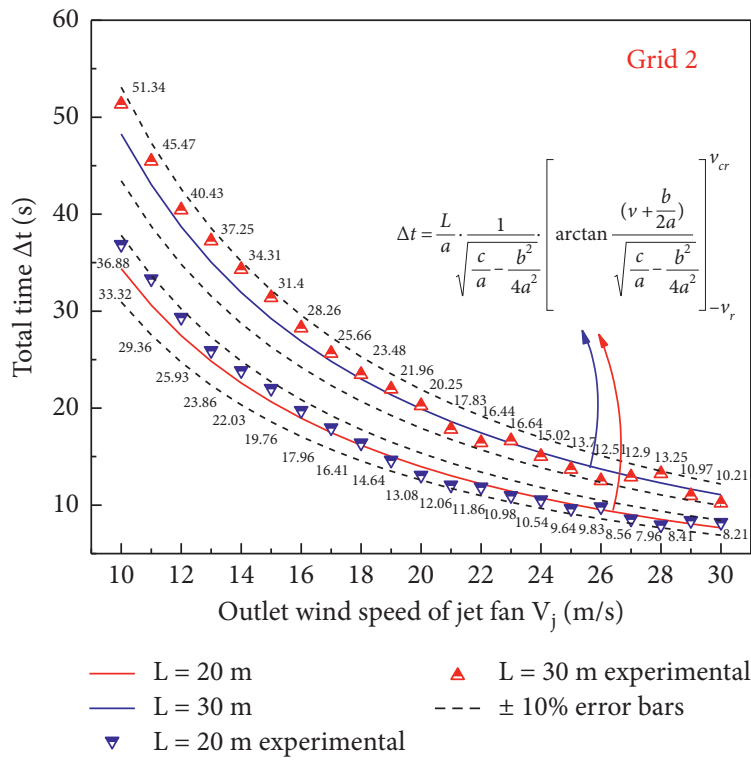

(c)
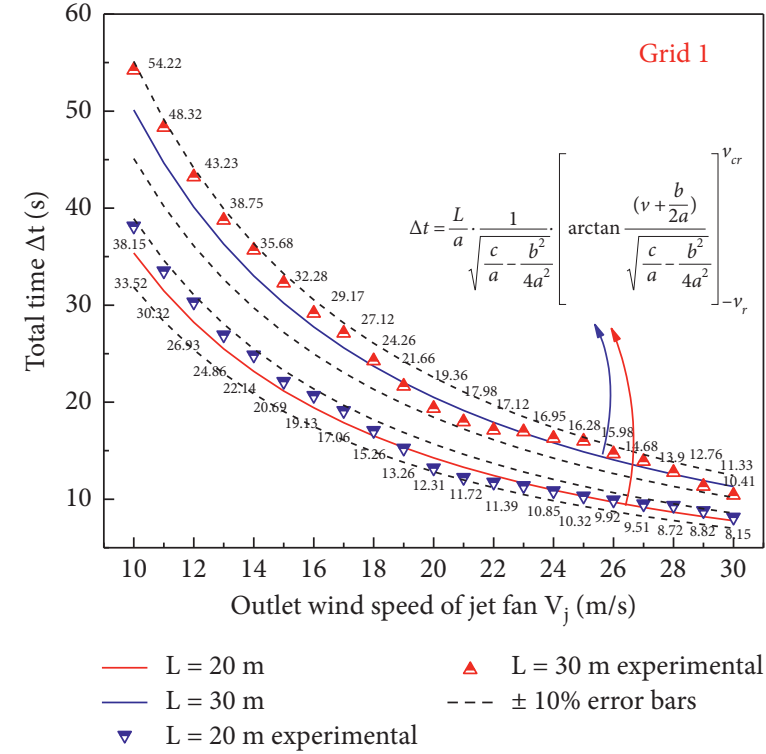

(b)

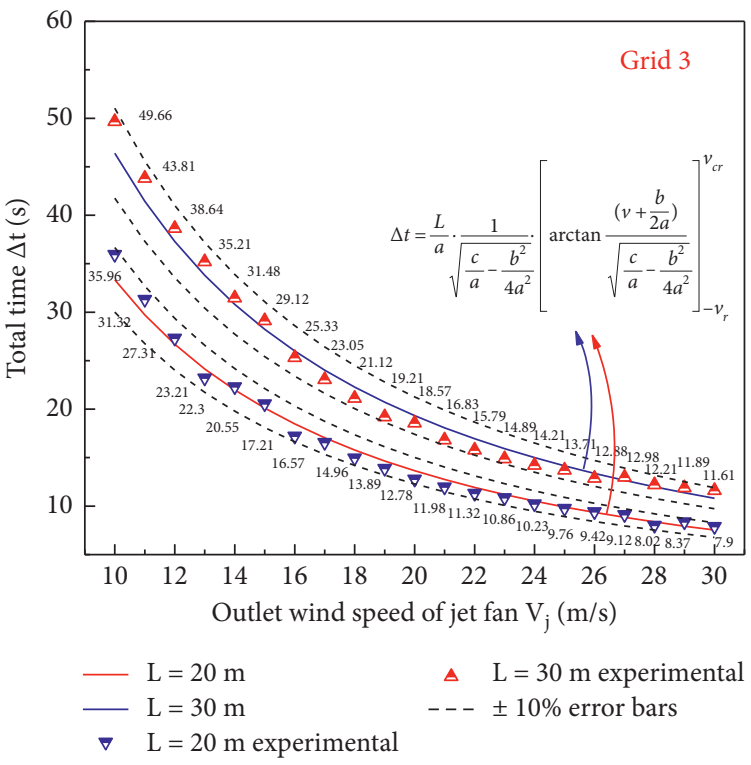

(d)

Figure 13: Continued. 


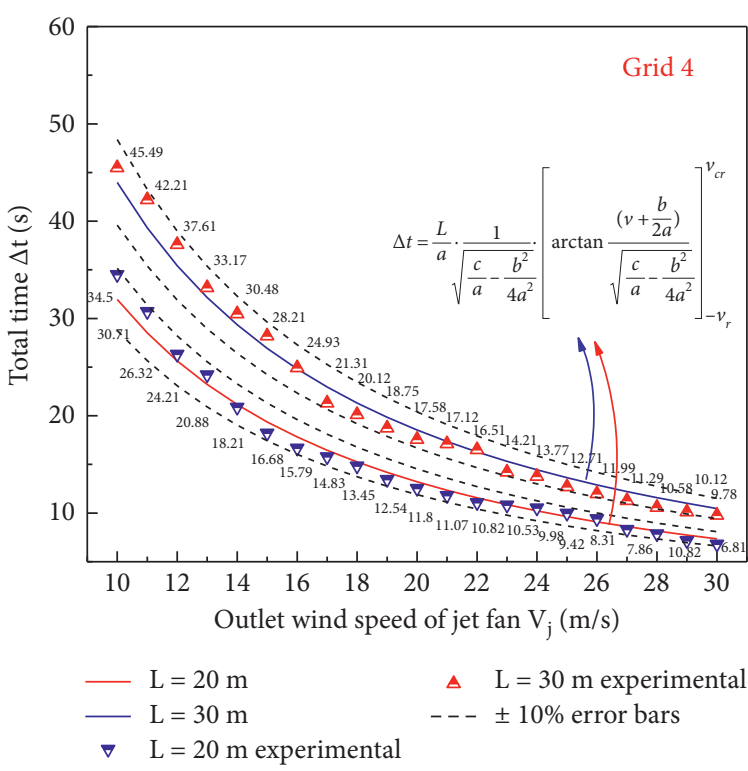

(e)

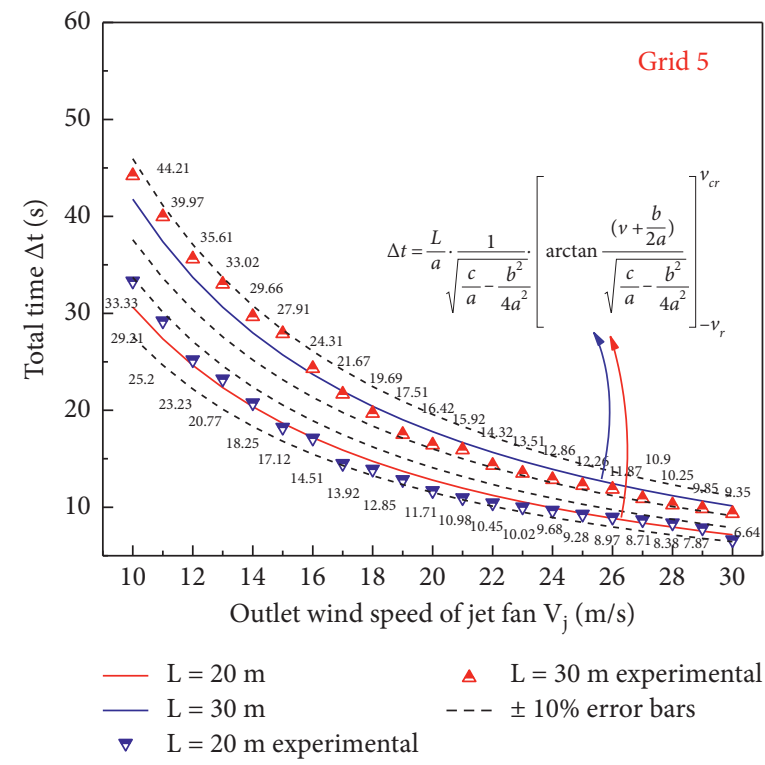

(f)

Figure 13: Time required to change with the wind speed of the jet fans: (a) no grid, (b) grid 1, (c) grid 2, (d) grid 3, (e) grid 4, and (f) grid 5.

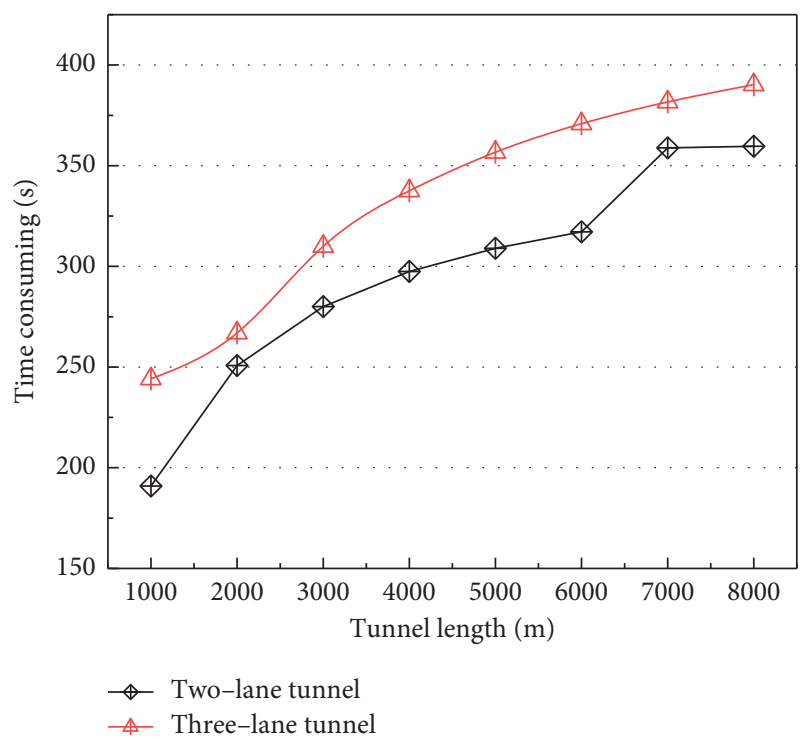

Figure 14: Time needed for the formation of stable reverse $v_{c r}$ in tunnels of different lengths.

\section{Conclusion}

(1) For the FAS system, the time from the start of the fire to the start of the exhaust fan is about $160 \mathrm{~s}$, close to 3 minutes. When the jet fans are fully operational, the time needed to form a stable critical wind speed is about $400 \mathrm{~s}$, which is close to 7 minutes; that exceeds the 5 minutes needed for the fire to reach its peak heating power.

(2) The time needed for the critical wind speed in the tunnel to go from the normal operating piston wind to the emergency ventilation mode is inversely proportional to the comprehensive resistance coefficient and also has a linear function with the reciprocal of the tunnel target wind speed. The air velocity in tunnels with different lengths decreases from the traffic piston wind speed to the critical wind speed in about 0.5 to 2 minutes.

(3) When the jet fans are used as the power, the time required for the airflow in the tunnel from the traffic piston wind state to the formation of reverse critical wind speed is between 3 and 7 minutes.

The above research results on the time factor rules have a guiding significance for the preparation of tunnel hardware linkage control plans and the setting of initial conditions for CFD fire simulation.

\section{Data Availability}

The data used to support the findings of this study are available from the corresponding author upon request.

\section{Conflicts of Interest}

The authors declare that there are no conflicts of interest regarding the publication of this paper.

\section{Acknowledgments}

This research was supported by National Natural Science Foundation of China (no. 51678530).

\section{References}

[1] H. Ingason and Y. Z. Li, "Model scale tunnel fire tests with longitudinal ventilation," Fire Safety Journal, vol. 45, no. 6-8, pp. 371-384, 2010.

[2] H. Ingason, Y. Z. Li, and A. Lönnermark, "Runehamar tunnel fire tests," Fire Safety Journal, vol. 71, pp. 134-149, 2015. 
[3] L. Chen, W. Zhu, X. Cai, L. Pan, and G. Liao, "Experimental study of water mist fire suppression in tunnels under longitudinal ventilation," Building and Environment, vol. 44, no. 3, pp. 446-455, 2009.

[4] E. J. Lee, C. B. Oh, K. C. Oh, Y. H. Yoo, and H. J. Shin, "Performance of the smoke extraction system for fires in the Busan-Geoje immersed tunnel," Tunnelling and Underground Space Technology, vol. 25, no. 5, pp. 600-606, 2010.

[5] Y. Li and H. Ingason, "The fire growth rate in a ventilated tunnel fire," Fire Safety Science, vol. 10, pp. 347-258, 2011.

[6] Z. Yuan, B. Lei, and A. Kashef, "Reduced-scale experimental research on fires in tunnels with natural ventilation," Procedia Engineering, vol. 62, pp. 907-915, 2013.

[7] L.-X. Yu, F. Liu, Y.-Q. Liu, M.-C. Weng, and S.-J. Liao, "Experimental study on thermal and smoke control using transverse ventilation in a sloping urban traffic link tunnel fire," Tunnelling and Underground Space Technology, vol. 71, pp. 81-93, 2018.

[8] M. Seike, N. Kawabata, and M. Hasegawa, "Quantitative assessment method for road tunnel fire safety: development of an evacuation simulation method using CFD-derived smoke behavior," Safety Science, vol. 94, pp. 116-127, 2017.

[9] E. Kim, J. P. Woycheese, and N. A. Dembsey, "Fire dynamics simulator (version 4.0) simulation for tunnel fire scenarios with forced, transient, longitudinal ventilation flows," Fire Technology, vol. 44, no. 2, pp. 137-166, 2007.

[10] S. Gannouni and R. Ben Maad, "Numerical analysis of smoke dispersion against the wind in a tunnel fire," Journal of Wind Engineering and Industrial Aerodynamics, vol. 158, pp. 61-68, 2016.

[11] M. Cha, S. Han, J. Lee, and B. Choi, "A virtual reality based fire training simulator integrated with fire dynamics data," Fire Safety Journal, vol. 50, pp. 12-24, 2012.

[12] C.-W. Chiu, T. Lu, H.-T. Chao, and C.-M. Shu, "Performance assessment of video-based fire detection system in tunnel environment," Tunnelling and Underground Space Technology, vol. 40, pp. 16-21, 2014.

[13] S. Gannouni and R. B. Maad, "Numerical study of the effect of blockage on critical velocity and backlayering length in longitudinally ventilated tunnel fires," Tunnelling and Underground Space Technology, vol. 48, pp. 147-155, 2015.

[14] S.-X. Sun, Y.-X. Zhang, P.-S. Lei, and J.-M. Wu, "Application conditions of Froude criteria for fire model test of highway tunnel," China Journal of Highway and Transport, vol. 29, no. 5, pp. 103-108, 2016.

[15] J. Rong, D. Zhou, W. Yao, W. Gao, J. Chen, and J. Wang, "Fire flame detection based on GICA and target tracking," Optics \& Laser Technology, vol. 47, pp. 283-291, 2013.

[16] K. Muhammad, J. Ahmad, and S. W. Baik, "Early fire detection using convolutional neural networks during surveillance for effective disaster management," Neurocomputing, vol. 288, pp. 30-42, 2018.

[17] B. C. Ko, K.-H. Cheong, and J.-Y. Nam, "Fire detection based on vision sensor and support vector machines," Fire Safety Journal, vol. 44, no. 3, pp. 322-329, 2009.

[18] C. Yu, Z. Mei, and X. Zhang, "A real-time video fire flame and smoke detection algorithm," Procedia Engineering, vol. 62, pp. 891-898, 2013.

[19] D. Alvear, O. Abreu, A. Cuesta, and V. Alonso, "Decision support system for emergency management: road tunnels," Tunnelling and Underground Space Technology, vol. 34, pp. 13-21, 2013.

[20] E. Ronchi, P. Colonna, J. Capote, D. Alvear, N. Berloco, and A. Cuesta, "The evaluation of different evacuation models for assessing road tunnel safety analysis," Tunnelling and Underground Space Technology, vol. 30, pp. 74-84, 2012.

[21] M. Kinateder, E. Ronchi, D. Gromer et al., "Social influence on route choice in a virtual reality tunnel fire," Transportation Research Part F: Traffic Psychology and Behaviour, vol. 26, pp. 116-125, 2014.

[22] D. Nilsson, M. Johansson, and H. Frantzich, "Evacuation experiment in a road tunnel: a study of human behaviour and technical installations," Fire Safety Journal, vol. 44, no. 4, pp. 458-468, 2009.

[23] J. Modic, "Fire simulation in road tunnels," Tunnelling and Underground Space Technology, vol. 18, no. 5, pp. 525-530, 2003.

[24] National standards of the People's Republic of China, Code for Design of Automatic Fire Alarm System (GB 50116-2013), China Planning Press, Beijing, China, 2013.

[25] F. Yuan, "A fast accumulative motion orientation model based on integral image for video smoke detection," Pattern Recognition Letters, vol. 29, no. 7, pp. 925-932, 2008.

[26] Ministry of Public Security of the People's Republic of China, Code for Design of Foam Extinguishing System (GB 501512010, People's Publishing House, Beijing, China, 2010.

[27] People's Republic of China Industry Recommended Standards, Guidelines for Design of Ventilation of Highway Tunnels (JTG/T D70/2-02-2014), China Communications Press, Beijing, China, 2014. 